Sādhanā Vol. 40, Part 6, September 2015, pp. 1975-1987. (C) Indian Academy of Sciences

\title{
Structural equation model to investigate the factors influencing quality performance in Indian construction projects
}

\author{
S SHANMUGAPRIYA* and K SUBRAMANIAN \\ Department of Civil Engineering, Coimbatore Institute of Technology, \\ Coimbatore 641014, India \\ e-mail: sunmu20@gmail.com; drkscit@gmail.com
}

MS received 29 September 2014; accepted 12 April 2015

\begin{abstract}
Indian construction industry has seen remarkable growth and it is an integral part of the economy with massive foreign investments which demands quality construction. The pressure to reduce time and cost of construction increases the risk on the part of stakeholders with respect to quality and safety of the construction. The problem is serious and dangerous in developing countries like India which requires focus and attention for sustained growth in construction sector. This research reports on the adoption and development of structural equation model to study the fundamental relationship between five enablers of European Foundation for quality management (EFQM) framework to improve the quality performance in Indian construction projects. Data collected from clients, contractors and consultants of Indian construction industry through questionnaire survey was used to analyze the conceptual framework using smart PLS software. The conceptual model in this research includes eight hypotheses and T-statistics values is used for checking the significance of the hypothesis. The findings of the study revealed that leadership factor has strongest total effect on people factor (Path coefficient $=0.77$ ) and process factor has strongest effect in achieving the goals of quality performance improvement in construction projects (Path coefficient $=0.7$ ). The results indicate that Indian construction organizations must give top priority to leadership and process related problems in various phases of the project to result in continuous improvement in quality performance.
\end{abstract}

Keywords. Quality performance; Partial Least Squares (PLS); EFQM model; measurement model; structural model; construction industry.

${ }^{*}$ For correspondence 


\section{Introduction}

Indian construction industry is now a highly dynamic sector, and its operating environment, industry structures and product characteristics are changing at an ever-increasing rate. World Trade organization and Globalization have made way for multinational companies to start business in India, which the Indian business has to contend with. Globalization has brought about huge changes in customer expectations and professionalism in business management to result in short gestation period of projects, competitive cost structure, high standards of quality and safety, high breed financial models, etc., all to global standards. International organizations are well conversant with such standards which have generated high level of competition in terms of technology, finance, efficiency and management. The construction industry is moving towards achieving higher quality to survive in the global competition. Quality in construction industry is meeting the predetermined requirements and specifications. It is a business strategy for winning over customers from the competitors. Successful organizations design, deploy and demonstrate to their customers appropriate management system to deliver quality product and services. The quality improvement in an organization is done with quality awards like European Foundation for Quality Management (EFQM) excellence model. The aim of this research is to study how the five enabler's criteria of EFQM framework can provide the means of achieving quality performance improvement in Indian construction projects. This paper presents the development of partial least squares path model for quality performance improvement and testing the casual relationship between five enablers criteria for the proposed eight hypotheses, with statistical investigations carried out using SPSS and smart PLS software to analyse and validate the model. The results of the model are expected to provide insights into the adoption of five enablers of EFQM framework in Indian construction projects and their effect on quality performance improvement.

\section{European quality award}

The model of the European Quality award consists of enablers and results. The enablers are leadership, people, policy and strategy, partnership and resources and process. The results are customer satisfaction, people satisfaction, impact on society and business results which are the measure of the level of output attained by the organization. Chinda \& Mohamed (2007) reported the use of structural equation modeling technique to test the causal relationships between key elements of safety culture using EFQM Model. In this study the four results criteria were combined into single construct as goals of safety performance. Vijande \& Gonzalez (2007) conducted a study for measuring TQM implementation following European Quality Award Model in Spanish manufacturing and service firms and also provided the empirical evidence on the relationship between total quality management practices and organizational performance using structural equation modeling. Ismail et al (2011) conducted a study to find out whether EFQM model can be successfully implemented in small and medium sized enterprise of developing countries. The results of his study indicated that EFQM gives a very good outcome for continuous improvement in private organizations towards achieving quality. Mahalli (2013) conducted a survey research in Iran steel industry with the purpose of measuring organizational performance based on enablers of EFQM framework. Process and Partnership \& resources are considered as strong sides towards achieving goals and excellence. 


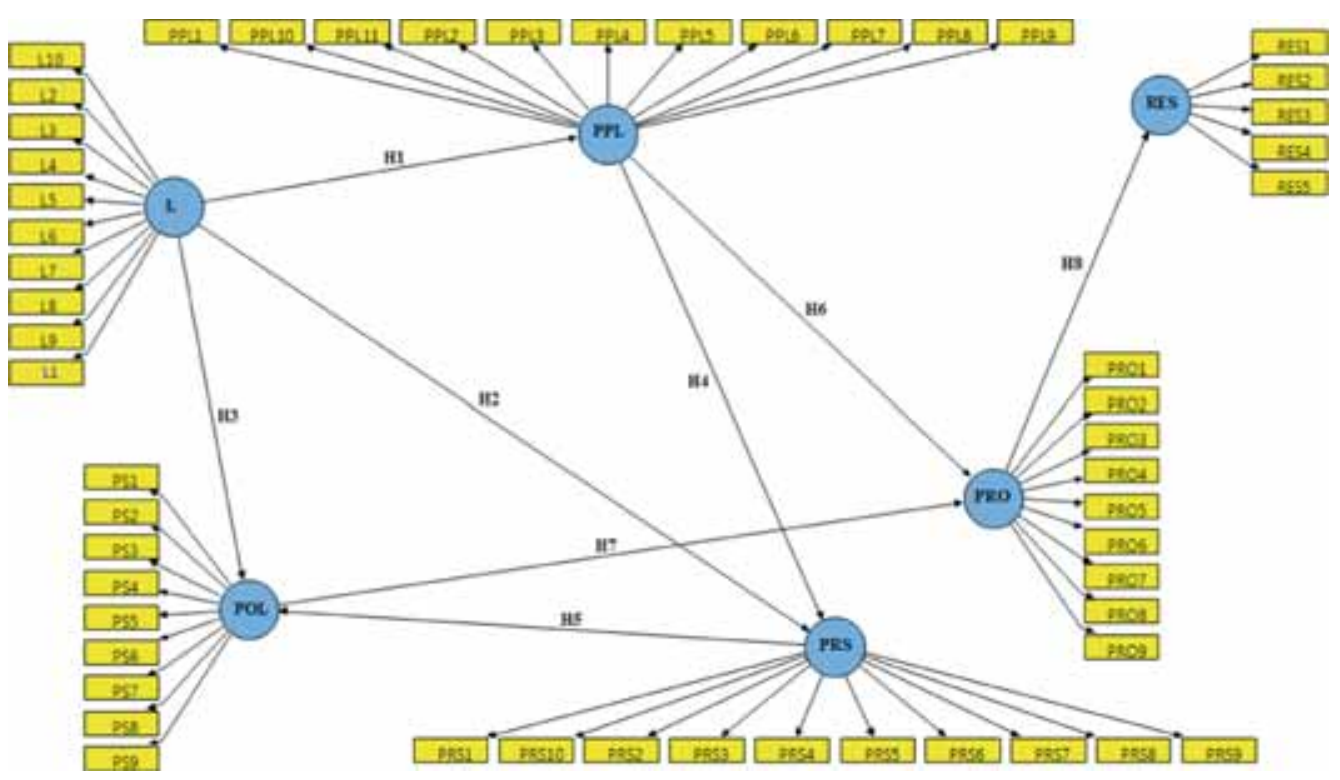

Figure 1. Initial conceptual PLS SEM Model for Quality performance improvement.

\section{PLS path model and hypothesis}

The theoretical framework developed in this research is based on EFQM framework as shown in figure 1. With an extensive review of quality management literatures, structural equation model using component based PLS path modelling is constructed by setting up eight hypotheses with 49 attributes for five enablers and five attributes for results.

H1 - There is a positive and significant relationship between leadership (L) and people (PPL). $\mathrm{H} 2$ - There is a positive and significant relationship between leadership (L) and partnership \& resources (PRS).

H3 - There is a positive and significant relationship between leadership (L) and policy \& strategy (POL).

H4 - There is a positive and significant relationship between people (PPL) and partnership \& resources (PRS).

H5 - There is a positive and significant relationship between partnership \& resources (PRS) and policy \& strategy (POL).

H6 - There is a positive and significant relationship between people (PPL) and process (PRO).

H7 - There is a positive and significant relationship between policy \& strategy (POL) and process (PRO).

H8 - There is a positive and significant relationship between process (PRS) and results (RES)

\subsection{Leadership $(L)$}

Leadership is considered as the most influential element for quality performance improvement in construction industry and 10 attributes are included under this enabler as indicators - Role model for cultural excellence in quality (L1), Responsible for quality performance (L2), Specifying quality objectives (L3), Commitment (L4), Encouraging the employees (L5), Acknowledgement 
and rewarding employees (L6), Collaborate employees in quality training (L7), Updating the knowledge (L8), Plan detailing the different stages of changes in project (L9) and Measure and review the effectiveness of quality (L10).

\subsection{Partnership and resources (PRS)}

This enabler emphases on having and implementing a clear methodology to plan, develop, enhance, and review the human, information, financial, materials and technological resources of the project such that it satisfies the organization objectives by incorporating the needs of the customers, the organization and the individuals working in the project. In the conceptual framework, nine attributes are included under this enabler - Long term relations with the suppliers (PRS1), Suppliers help in providing technical assistance (PRS2), Quality agreement with the suppliers (PRS3), Quality documentation (PRS4), Specifying right quantity of materials (PRS5), Allocation of financial resources to meet the actual budgeted cost (PRS6), Proper allocation of equipment and materials (PRS7), Using technology with higher operational efficiency (PRS8), Focus on research and development (PRS9), and Site quality inspection of materials (PRS10).

\subsection{People (PPL)}

This enabler focuses on accomplishment of continuous improvement in people management through their skills and capabilities developed through recruitment, training and progression in their career. This people enabler is manifested by 11 attributes in the conceptual model - Planning and managing of peoples resources (PPL1), Incentives and awards (PPL2), Knowing up of quality as their responsibility by project participants (PPL3), Recruitment depending upon their skills and experience (PPL4), Two way communication (PPL5), People are responsible for end results of the quality (PPL6), Giving the opportunity to implement solutions (PPL7), Welfare program (PPL8), Motivation systems (PPL9), Training (PPL10), Suggestions, feedback and complaint system (PPL11).

\subsection{Policy and strategy (POL)}

This enabler highlights on establishing the objectives and goals of development and implementation of quality plan in construction projects, with identifying organization mission and vision. Nine attributes are included under this enabler in conceptual framework - Satisfying the needs and expectation of the stakeholders (PS1), Periodic review and update of policies (PS2), Benchmarking techniques (PS3), Swot Analysis (PS4), Specific and measurable objectives for quality policies (PS5), Systematic measurement of quality and non-quality cost (PS6), Systematic procedures to plan, evaluate and control project goal achievements (PS7), Systematic procedures based on information from performance measurement of projects, research, learning and external related activities (PS8), and Systematic assessment of effectiveness of projects (PS9).

\subsection{Process (PRO)}

This enabler focuses on the extent of the organization's commitment in setting and implementing a complete methodology to plan, execute and develop work systems for all activities within the organization. Under this enabler nine attributes are included - Systematic design and management of process (PRO1), Comprehensive documents (PRO2), Regular assessment of process to bring 
in change and improvement (PRO3), Using system of indicators to revise the change (PRO4), Efficient behaviour patterns through work process (PRO5), Improvement of process through innovative techniques (PRO6), Satisfying customers' needs (PRO7), Improvement of customers relationships (PR08), and Conformance to codes and standards (PRO9).

\section{Research methodology}

\subsection{Questionnaire survey}

The research methodology for the current study has implemented questionnaire survey to test the conceptual model of quality performance improvement in Indian construction sector based on EFQM framework. To identify indicators for six latent constructs influencing goals of improving quality performance, extensive literature review was carried out along with interaction between construction practitioners through pilot study The result criteria in the conceptual framework based on EFQM model includes five attributes i.e. Project will be finished as per the customer's need in terms of quality (RES1), Employee involvement and their skills will be improved (RES2), Unnecessary costs due to reworks and others will be decreased (RES3), Firms image and status will be improved (RES4), New work methods will be implemented to improve the quality (RES5). Questionnaire is framed and then it is distributed to clients, contractors and consultants of Indian construction industry for the main survey. Questionnaire for the survey consists of two parts with first part designed to gather information on organization's profile and personal information of the respondent. The second part of the questionnaire includes 52 statements that tend to improve the quality in construction industry under six constructs i.e., leadership, people, partnership \& resources, policy \& strategy, process and results. Each statement is designed to elicit the respondents' opinions on the different attributes in the context of quality enhancement using a 5-point likert scale, with point 1 representing very little effect, point 2 representing little effect, 3 point representing average effect, 4 point representing high effect and point 5 representing very high effect. This approach enables the evaluation of the respondent's perception and commitment towards enhancement of quality. The indicators gathered from literature review and field study provide the hypothetical basis to develop the conceptual model as shown in figure 1 using partial least square SEM. Questionnaire has been distributed to about 150 respondents and got the filled questionnaire back from 113 respondents at a response rate of about $75 \%$. The majority of the respondents (49\%) are working with contractors organizations followed by clients $(30 \%)$ and consultants $(20 \%)$.

\subsection{Data analysis}

Statistical investigation and analysis of this research is based on component-based partial least squares structural equation modeling. There are two types of assessment carried out in the conceptual model - Assessment of outer measurement model and Assessment of inner structural model. The analysis and validity of the model is carried out using smart PLS software (Ringle et al 2005).

\subsection{Assessment of outer measurement model}

In the theoretical framework, the outer measurement model specifies the relationship between enablers and their indicators. Measurement model is assessed for both convergent validity 
and discriminant validity. The measure of internal consistency is convergent validity which is estimated to ensure that indicators assumed to measure each enabler actually measure them and not measuring another enabler. In partial least squares path modeling, three tests can be used to determine the convergent validity of the measured constructs i.e., Cronbach's alpha, Composite reliability scores $(\rho \mathrm{c})$ and Average variance extracted (AVE). Cronbach's alpha is the coefficient of reliability of construct. It measures how well a set of indicators or variables measures a single enabler latent construct. It assumes that all the indicators measuring a construct are equally reliable in PLS path models. Composite reliability scores $(\rho c)$ is similar to Cronbach alpha, but composite reliability uses different item loadings of the indicators obtained within the theoretical model. Most of the past researches have suggested a common threshold value for a good model is to have cronbach's alpha value more than 0.6 and composite reliability scores more than 0.7 (Rahman et al 2013). Average variance extracted (AVE) measures the amount of variance that a latent enabler variable captures from its measurement items or indicators relative to the amount of variance due to measurement errors. Fornell \& Larcker (1981) stated that AVE should be higher than 0.5 which means that at least $50 \%$ of measurement variance is captured by the latent enabler variables. Indicators having low loadings should be eliminated as they have very little explanatory power to the model (Aibinu \& Al-Lawati 2010). The result of indicators reliabilities and convergent validity after the elimination of indicators with low correlation values is shown in figure 2.

Discriminant validity indicates the extend of the given enabler is different from other enablers and two measures are used for assessing it i.e., Fornell-Larcker criterion and Cross loadings test (Hulland 1999). The discriminant validity at construct level is assessed by Fornell \& Larcker

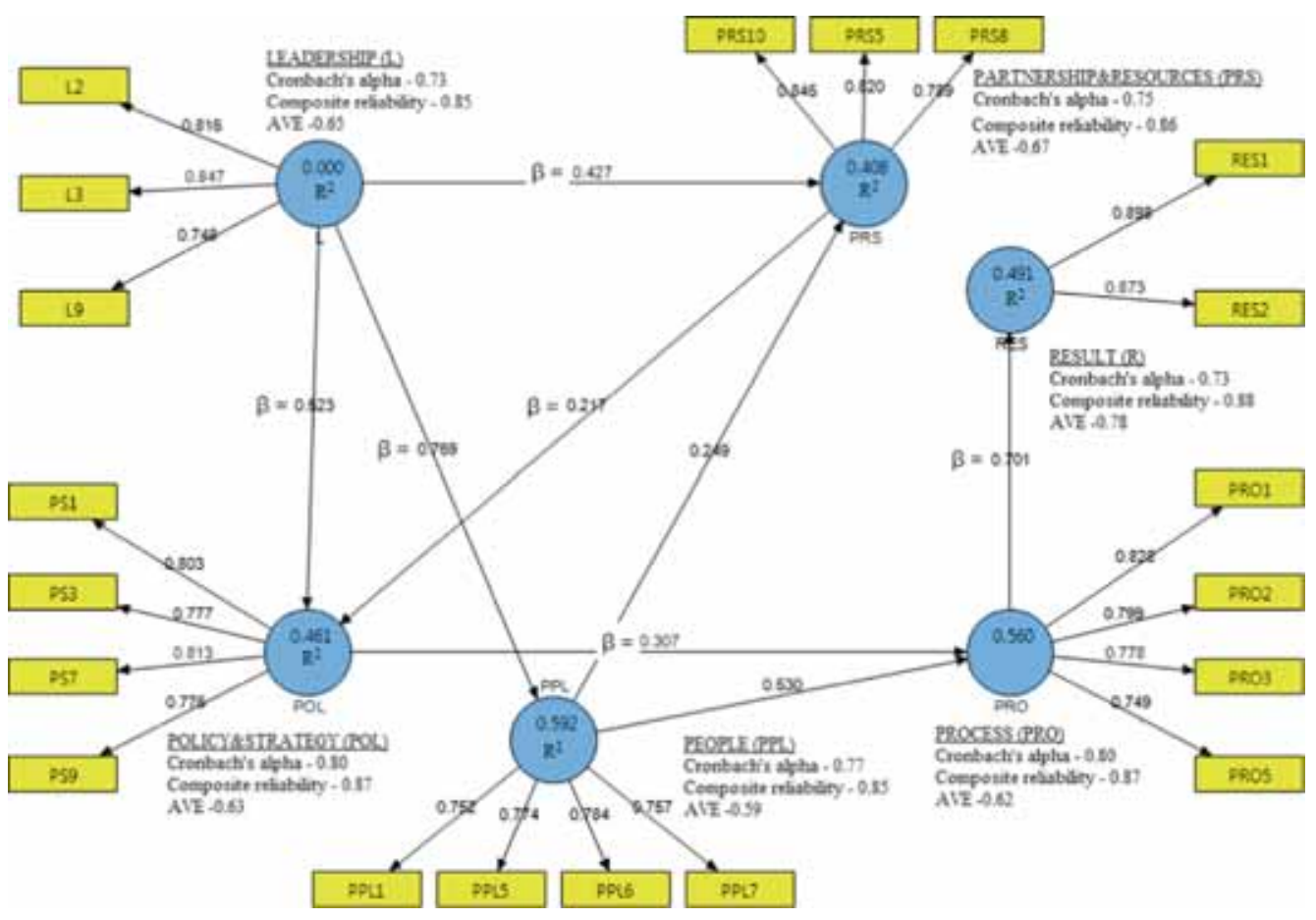

Figure 2. Final PLS Path model for quality performance improvement. 
Table 1. Correlation matrix of enablers.

\begin{tabular}{lcccccc}
\hline & L & POL & PPL & PRO & PRS & RES \\
\hline L & $\mathbf{0 . 8 0}$ & 0 & 0 & 0 & 0 & 0 \\
POL & 0.66 & $\mathbf{0 . 7 9}$ & 0 & 0 & 0 & 0 \\
PPL & 0.71 & 0.57 & $\mathbf{0 . 7 7}$ & 0 & 0 & 0 \\
PRO & 0.69 & 0.61 & 0.70 & $\mathbf{0 . 7 9}$ & 0 & 0 \\
PRS & 0.62 & 0.54 & 0.58 & 0.68 & $\mathbf{0 . 8 2}$ & 0 \\
RES & 0.70 & 0.55 & 0.69 & 0.70 & 0.56 & $\mathbf{0 . 8 9}$ \\
\hline
\end{tabular}

Table 2. Cross loading test for discriminant validity of enabler.

\begin{tabular}{lcccccc}
\hline & L & POL & PPL & PRO & PRS & RES \\
\hline L2 & $\mathbf{0 . 8 2}$ & 0.51 & 0.64 & 0.61 & 0.63 & 0.57 \\
L3 & $\mathbf{0 . 8 5}$ & 0.55 & 0.61 & 0.57 & 0.42 & 0.60 \\
L9 & $\mathbf{0 . 7 5}$ & 0.53 & 0.61 & 0.49 & 0.43 & 0.52 \\
PS1 & 0.44 & $\mathbf{0 . 8 0}$ & 0.36 & 0.41 & 0.44 & 0.36 \\
PS3 & 0.52 & $\mathbf{0 . 7 8}$ & 0.47 & 0.50 & 0.47 & 0.40 \\
PS7 & 0.62 & $\mathbf{0 . 8 1}$ & 0.51 & 0.54 & 0.38 & 0.55 \\
PS9 & 0.48 & $\mathbf{0 . 7 8}$ & 0.43 & 0.45 & 0.42 & 0.40 \\
PPL1 & 0.53 & 0.43 & $\mathbf{0 . 7 5}$ & 0.51 & 0.40 & 0.47 \\
PPL5 & 0.61 & 0.42 & $\mathbf{0 . 7 7}$ & 0.60 & 0.50 & 0.59 \\
PPL6 & 0.64 & 0.40 & $\mathbf{0 . 7 8}$ & 0.60 & 0.48 & 0.60 \\
PPL7 & 0.58 & 0.49 & $\mathbf{0 . 7 6}$ & 0.44 & 0.39 & 0.45 \\
PRO1 & 0.60 & 0.56 & 0.68 & $\mathbf{0 . 8 3}$ & 0.52 & 0.67 \\
PRO2 & 0.51 & 0.45 & 0.50 & $\mathbf{0 . 8 0}$ & 0.56 & 0.49 \\
PRO3 & 0.53 & 0.52 & 0.53 & $\mathbf{0 . 7 8}$ & 0.50 & 0.54 \\
PRO5 & 0.54 & 0.35 & 0.48 & $\mathbf{0 . 7 5}$ & 0.57 & 0.49 \\
PRS10 & 0.54 & 0.46 & 0.51 & 0.58 & $\mathbf{0 . 8 4}$ & 0.49 \\
PRS5 & 0.50 & 0.41 & 0.45 & 0.58 & $\mathbf{0 . 8 2}$ & 0.45 \\
PRS8 & 0.47 & 0.46 & 0.46 & 0.50 & $\mathbf{0 . 7 9}$ & 0.43 \\
RES1 & 0.70 & 0.52 & 0.63 & 0.65 & 0.55 & $\mathbf{0 . 9 0}$ \\
RES2 & 0.54 & 0.44 & 0.59 & 0.59 & 0.44 & $\mathbf{0 . 8 7}$ \\
\hline
\end{tabular}

(1981) criterion and suggests that an enabler shares more variance with its assigned indicators than with any enablers. The AVE of each enabler should be greater than enabler's highest squared correlation with any other variable. The correlation matrix of the enablers is presented in table 1 in which main diagonals are the square root of average variance extracted (AVE).

The second criterion for discriminant validity is cross loadings, where the indicators loadings on its own enabler must be higher than all of its cross loadings with other enablers (Chin 1998). The results of cross loadings are tabulated in table 2 and both the tests confirm the discriminant validity of the enablers in the model.

\subsection{Assessment of inner structural model}

The construct measures in measurement model are confirmed as reliable and valid, the next step is to assess the structural model results. This involves examining the model's predictive capabilities and the relationships between the constructs. For assessing the inner structural 
Table 3. Multi-collinearity assessment.

\begin{tabular}{lccc}
\hline Set of predictor variable & Criterion variable & $\begin{array}{c}\text { Formal detection } \\
\text { tolerance }\end{array}$ & $\begin{array}{c}\text { Variance inflation } \\
\text { factor }\end{array}$ \\
\hline Leadership and people & Partnership \& resources & 0.408 & 2.45 \\
Leadership and partnership \& resources & Policy \& strategy & 0.617 & 1.62 \\
People and policy \& strategy & Process & 0.679 & 1.47 \\
\hline
\end{tabular}

model, criterion checked are Multi-collinearity assessment, T-statistic value and Path coefficient ( $\beta$ value), Effect size and Predictive relevance of the model.

4.4a Multicollinearity assessment of structural model: In structural models, it is essential to check whether any significant level of collinearity exist between predictor or explanatory variables. To check the collinearity the following sets of predictor constructs in path model as shown in table 3 is run using SPSS linear regression by finding the formal detection tolerance and variance inflation factor (VIF). The tolerance levels below 0.10 and VIF of 10 and above indicates that there is multi-collinearity problem (Henseler et al 2009). The results indicate that collinearity is not high between the predictor constructs as they are below the tolerance limits.

4.4b Path coefficient ( $\beta$ value) and T-statistics value: In PLS path models, structural model and significance of the hypothesis are tested by computing path coefficients ( $\beta$ value). Path models by partial least squares method does not require the data to be normally distributed, it is evaluated with squared multiple correlations $\left(R^{2}\right)$ for each latent endogenous variable which provides how well the model fits the hypothesized relationships. For assessing the significance of hypothesis, the bootstrapping procedure is used (Chin 1998). Bootstrapping procedure using 5,000 sub samples was performed to estimate the significance of the path coefficients. Table 4 shows the hypothesized path coefficient values along with the T- statistics (bootstrap) values.

The relationship between leadership and people is significant with $\beta=0.77$ and T-value $=17.36$ (Table value is 1.96 at $5 \%$ level of significance) has direct positive significant influence on people. The people enabler changes in direct proportion to leadership enabler with a coefficient of 0.77 . This indicates that a 100 point change in leadership will bring about 77 point changes in people enabler. The relationship between partnership \& resources enabler and policy $\&$ strategy enabler is insignificant with $\beta=0.22$ and T-value $=1.57$ (Table value is 1.96 at $5 \%$

Table 4. Path coefficient and T-statistics value.

\begin{tabular}{lcccccc}
\hline $\begin{array}{l}\text { Hypothetical } \\
\text { path }\end{array}$ & $\begin{array}{c}\text { Original } \\
\text { sample (O) }\end{array}$ & $\begin{array}{c}\text { Sample } \\
\text { mean (M) }\end{array}$ & $\begin{array}{c}\text { Standard deviation } \\
(\text { STDEV) }\end{array}$ & $\begin{array}{c}\text { Standard error } \\
(\text { STERR })\end{array}$ & $\begin{array}{c}\text { T statistics } \\
(\text { IO/STERRI) }\end{array}$ & Inference \\
\hline L-PPL (H1) & 0.77 & 0.77 & 0.04 & 0.04 & 17.36 & Significant \\
L-PRS (H2) & 0.43 & 0.43 & 0.11 & 0.11 & 3.73 & Significant \\
L-POL (H3) & 0.52 & 0.52 & 0.11 & 0.11 & 4.77 & Significant \\
PPL-PRS (H4) & 0.25 & 0.26 & 0.10 & 0.10 & 2.50 & Significant \\
PRS-POL (H5) & 0.22 & 0.22 & 0.14 & 0.14 & 1.57 & Insignificant \\
PPL-PRO (H6) & 0.53 & 0.52 & 0.08 & 0.08 & 6.24 & Significant \\
POL-PRO(H7) & 0.31 & 0.31 & 0.13 & 0.13 & 2.45 & Significant \\
PRO-RES(H8) & 0.70 & 0.70 & 0.06 & 0.06 & 12.31 & Significant \\
\hline
\end{tabular}


level of significance) has direct positive insignificant influence on policy \& strategy. The policy and strategy enabler changes in direct proportion to partnership \& resources enabler with a coefficient of 0.22 . This indicates that a 100 point change in partnership \& resources will bring about 22 point changes in policy \& strategy enabler.

4.4c Measuring the value of $R^{2}$ : In PLS path models, the squared correlation values of 0.67 , 0.33 and 0.19 are considered as substantial, moderate and weak respectively (Chin 1998). The $R^{2}$ value of each latent endogenous construct as shown in figure 3 is greater than 0.4 and the values are considered to be moderate.

4.4d Effect size $f^{2}$ : The effect size is the measure of impact of each predictor construct on the dependant construct. In the PLS path model, when an independent construct is omitted from the model, it measures the changes in squared correlation values and determine whether the omitted independent construct has substantive effect on the value of dependent construct. The formula for calculating effect size $f^{2}$ (Chin 1998) is given by the following equation.

$$
f^{2}=\frac{R^{2} \text { included }-R^{2} \text { excluded }}{1-R^{2} \text { included }} .
$$

The effect of predictor independent construct is large at the structural level if $f^{2}$ is 0.35 and it is medium if $f^{2}$ is 0.15 and small if $f^{2}$ is 0.02 (Cohen 1988) and the results and inference are tabulated in table 5 .

4.4e Model's predictive relevance: The quality of partial least squares path model is evaluated by calculating $\mathrm{Q}^{2}$ statistics. It is the capability of the model to predict by repeating the observed values by the model itself through blind folding procedures (Tenenhaus et al 2005). In structural

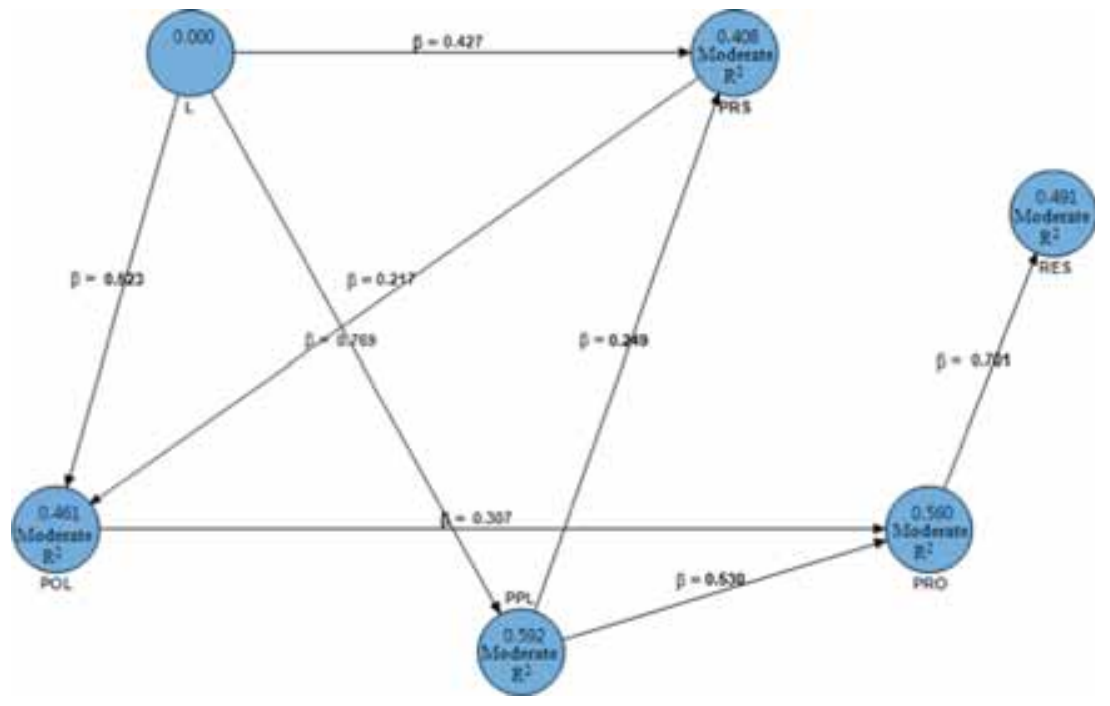

Figure 3. Measuring the value of $R^{2}$. 
Table 5. Effect size $f^{2}$.

\begin{tabular}{lccccc}
\hline \multirow{2}{*}{ Dependent construct } & $\begin{array}{c}\text { Independent } \\
\text { construct }\end{array}$ & $R^{2}$ (included) & $R^{2}$ (excluded) & Effect size & Inference \\
\hline Partnership & Leadership & 0.408 & 0.335 & 0.12 & Small to medium effect \\
People & Leadership & 0.592 & 0 & 1.45 & Large effect \\
Policy & Leadership & 0.461 & 0.295 & 0.30 & Medium to large effect \\
Policy & Partnership & 0.461 & 0.435 & 0.05 & Small to medium effect \\
Partnership & People & 0.408 & 0.386 & 0.04 & Small to medium effect \\
Process & People & 0.56 & 0.370 & 0.43 & Medium to large effect \\
Process & Policy & 0.56 & 0.496 & 0.15 & Medium effect \\
\hline
\end{tabular}

Table 6. Predictive relevance of the model by cross validated redundancy approach.

\begin{tabular}{lccccc}
\hline $\begin{array}{l}\text { Latent endogenous } \begin{array}{c}\text { Latent exogenous } \\
\text { construct }\end{array} \\
\text { construct }\end{array}$ & $\mathrm{Q}^{2}$ (included) & $\mathrm{Q}^{2}$ (excluded) & $\mathrm{q}^{2}$ & effect size & Inference \\
\hline Partnership & Leadership & 0.28 & 0.23 & 0.07 & Small to medium effect \\
Policy & Leadership & 0.29 & 0.19 & 0.14 & Small to medium effect \\
Policy & Partnership & 0.29 & 0.27 & 0.02 & Small to medium effect \\
Partnership & People & 0.28 & 0.26 & 0.02 & Small to medium effect \\
Process & People & 0.34 & 0.22 & 0.18 & Medium to large effect \\
Process & Policy & 0.34 & 0.30 & 0.06 & Small to medium effect \\
\hline
\end{tabular}

equation models, $\mathrm{Q}^{2}$ greater than zero means the model has predictive relevance and less than zero means the model lacks predictive relevance. As a relative measure of predictive relevance, values of $0.02,0.15$, and 0.35 indicate that an exogenous construct has a small, medium, or large predictive relevance for a selected endogenous construct. By using blindfolding procedures, two types of $\mathrm{Q}^{2}$ statistics can be estimated - Cross validated communality $\left(\mathrm{H}^{2}\right)$ and Cross validated redundancy $\left(\mathrm{F}^{2}\right)$.

The cross validated communality approach measures the capability of the model to predict the indicators directly from their enablers by cross validation using measurement model. The cross validated redundancy approach uses the estimates of the path model to predict eliminated data points using both inner structural model and outer measurement model. In the developed PLS Path model, Cross validated redundancy approach is applied to predict the omitted data points. The $\mathrm{q}^{2}$ effect size for the predictive relevance of the model and inference are tabulated in table 6 .

In the path model, the predictive relevance $\mathrm{q}^{2}$ effect size of people has a value of 0.18 which indicates that the people construct has medium to large predictive relevance on process.

\section{Mediating effects in the model}

In this study, in addition to the direct effect of construct, indirect effects of the construct through two or more mediating construct is investigated. In PLS path model, leadership construct has a direct effect on people and indirect effect with process through the mediating constructs policy \& strategy, people and partnership \& resources. It has both direct and indirect effects with partnership \& resources and policy and strategy, for which total effects is estimated by summing up direct and indirect effects. The result of mediating effect in the path model is presented in table 7. The findings indicate that leadership $(\mathrm{L}=0.77)$ has the strongest total effect on people 
followed by process $(\mathrm{PRO}=0.7)$ having strong total effect on the results of achieving the goals of quality performance.

\section{Global fit index of the model}

Goodness-of-Fit (GOF) is used as an index for the overall fit of the model, to validate the partial least squares path model globally (Tenenhaus et al 2005). GOF is the geometric mean of the average communality and the average $R^{2}$. For the global validation of PLS path model the cut off values lies between 0 and 1 resulting in GOF small $=0.1$, GOF medium $=0.25$, GOF large $=0.36$ (Akter et al 2011). In this model the global fit index is 0.53 , which indicates that empirical data fits the model very well. The value of $R^{2}$ and communality is given in table 8 for each enabler.

\section{Discussion}

This research has investigated the causal relationship among the five enablers namely leadership, people, partnership \& resources, policy \& strategy and process of EFQM framework and their adoption to achieve the goals of improvement in quality performance in Indian construction

Table 7. Mediating effects of the construct in the model.

\begin{tabular}{lccccc}
\hline Construct & Mediating construct & Direct effect & Indirect effect & Total effect & t-value \\
\hline L-PRS & PEO & 0.43 & 0.19 & 0.62 & 6.57 \\
L-PPL & - & 0.77 & 0 & 0.77 & 17.28 \\
L-POL & PEO, PRS & 0.52 & 0.13 & 0.66 & 10.18 \\
L-PRO & PEO, POL, PRS & 0 & 0.60 & 0.60 & 10.05 \\
L-RES & POL, PEO, PRS, PRO & 0 & 0.42 & 0.42 & 6.14 \\
PRS-POL & - & 0.22 & 0 & 0.22 & 1.58 \\
PRS-PRO & POL & 0 & 0.07 & 0.07 & 1.01 \\
PRS-RES & POL, PRO & 0 & 0.05 & 0.05 & 1.00 \\
PEO-PRS & - & 0.25 & 0 & 0.25 & 2.47 \\
PEO-POL & PRS & 0 & 0.05 & 0.05 & 1.46 \\
PEO-PRO & PRS, POL & 0.53 & 0.02 & 0.55 & 2.45 \\
PEO-RES & PRS, POL, PRO & 0 & 0.38 & 0.38 & 5.90 \\
POL-PRO & - & 0.31 & 0 & 0.31 & 2.45 \\
POL-RES & PRO & 0 & 0.22 & 0.22 & 2.34 \\
PRO-RES & - & 0.70 & 0 & 0.70 & 12.29 \\
\hline
\end{tabular}

Table 8. Global Fit Index of the model.

\begin{tabular}{lcc}
\hline Enablers & $R^{2}$ & Communality \\
\hline Leadership & 0 & 0.65 \\
People & 0.59 & 0.59 \\
Policy \& Strategy & 0.46 & 0.63 \\
Partnership \& Resources & 0.40 & 0.67 \\
Process & 0.56 & 0.62 \\
Results & 0.49 & 0.78 \\
Average & 0.42 & 0.66 \\
\hline
\end{tabular}


projects. The main purpose of this study is to apply component based structural equation modeling technique to investigate the factors influencing quality performance improvement in Indian construction projects with EFQM Excellence model as a guide. This advanced statistical technique is used to test the statistical adequacy of the proposed causal model to prove or disprove the hypothesized relationships. By using this technique, the influence of direct and indirect factors on quality improvement in construction projects can be understood. Even though, there have been many past studies by researchers on factors influencing quality performance, there is no study carried out on the applications of structural equation modeling to model the quality performance factors in Indian construction sector. The results provided from the analysis provides insight on quality performance factors and explain their relative importance to construction professionals which will help them to take appropriate managerial choices and to take corrective actions towards the most controlling factors.

The statistical results of the model indicate that all path coefficients are significant except partnership \& resources to policy \& strategy. The predictive accuracy of the model is determined by evaluating the value of $R^{2}$. The structural model results show that $59.2 \%$ of variability in people factor is explained by leadership factor followed by $56 \%$ variability in process related factor is explained by people factor and policy \& strategy factor. About $49.1 \%$ changes in goals of achieving the quality performance is explained by process related factor.

The model also exhibits predictive relevance and the results indicate that exogenous construct people has large predictive relevance on endogenous construct process $\left(q^{2}=0.18\right)$. The results of mediating analysis show that the latent factors leadership factor were found to have strongest direct effect on people (Direct effect $=0.77$ ) followed by policy \& strategy, partnership \& resources, process and results. The latent factor people has strongest direct effect on process (Direct effect $=0.55$ ) and Process has strongest direct effect in achieving the goals of quality performance (Direct effect $=0.70$ ). In PLS path model development, the model is modified by deleting the paths that have low correlations to optimize the fit of the model. The global fit index of the proposed model also ascertains that empirical data used fits the model and has sufficient explaining power.

\section{Conclusion and recommendation}

The results of the study indicate that construction industry must pay more significance on the following sub-factors to improve quality in the construction project to satisfy the customer's needs and for continuous improvement.

- Top management should have ability to identify the responsibilities of quality performance.

- Top management should be attached in relation to time, cost, and quality objectives.

- Leaders should provide plan detailing the different stages of change and secure the investment, resources and support needed to achieve the change.

- Man power resources of the project should be planned, managed for the improvement of quality objectives.

- Employees should be responsible for quality and end results of the project.

- Communication with the employees should be of two way communication.

- Employees should be given the opportunity to suggest and implement solutions to work problems.

- All the quality processes should be systematically designed and managed.

- Comprehensive documents should be available for the work methods and organizational processes. 
- All the process, procedures and products should be accessed regularly in an attempt to bring in change and improvement.

- Work processes should promote efficient behavior patterns throughout the project.

The outcome of this study can help the construction organizations to enhance the quality management systems by denoting to the important factors they need to put their focus and attention to result in continuous improvement of quality and reliability of the construction projects. Many matured organizations want to move forward and adopt advanced models like European Foundation for quality management (EFQM) and Malcolm Bridge National Quality Award (MBNQA) in their journey towards excellence. These models tend to integrate the various parts of the organization's management systems into a single management system for completeness and overall effectiveness of the projects carried out by the organizations. To improve the factors influencing quality performance in construction projects, commitment and ownership of the entire organization is essential. If the Leadership can motivate its people and sincerely develop and implement the process, the organization would grow continuously in executing the projects successfully and reach excellence within a short time.

\section{References}

Aibinu A A and Al-Lawati A M 2010 Using PLS- SEM technique to model construction organization's willingness to participate in e-bidding. Autom. Construct. 19(6): 714-724. doi: 10.1016/j.autcon. 2010.02.016

Akter S, Ambra J D and Ray P 2011 Trustworthiness in m-Health information services: An assessment of a hierarchical model with mediating and moderating effects using partial least squares (PLS). J. Am. Soc. Inf. Sci. Technol. 62(1): 100-116

Chin W W 1998 The partial least squares approach to structural equation modeling. Lawrence Erlbaum Associates, Mahwah, New Jersey

Chinda T and Mohamed S 2007 Causal relationships between enablers of Construction safety culture. In: Proceedings of the fourth international conference on accelerating innovation in engineering, management and technology, Gold Coast, Australia, pp. 438-445

Cohen J 1988 Statistical power analysis for the behavioural sciences. Lawrence Erlbaum Associates Hillsdale, New Jersey

Fornell C and Larcker D F 1981 Structural equation models with unobservable variables and measurement error: Algebra and statistics. J. Market. Res. 18(3): 328-388. doi: 10.2307/3150980

Henseler J, Ringle C M and Sinkovics R R 2009 The use of partial least squares path modeling in international marketing. Adv. Int. Market. 20(1): 277-319. doi: 10.1108/S1474-7979

Hulland J 1999 Use of partial least squares (PLS) in strategic management research: A review of four recent studies. Strategic Manag. J. 20(2): 195-204. doi: 10.1002/(SICI)1097-0266(199902)

Ismail W K W, Darestani H and Irani M A 2011 Quality excellence model: A review of researches in Developing countries. Int. J. Fundam. Psychol. Social Sci. 1(2): 35-38

Mahalli A F 2013 Applying the EFQM model in performance measuring of organization. Standard Res. J. Business Manag. 41(1): 41-51

Rahman I A, Memon A H, Abdul Azis A A and Abdullah N H 2013 Modeling causes of cost overrun in large construction projects with partial least square-SEM approach: Contractor's perspective. Res. J. Appl. Sci. Eng. Technol. 5(6): 1963-1972

Ringle C M, Wende S and Will S 2005 SmartPLS 2.0 (M3 Beta), Hamburg, Retrieved from: www.smartpls.de Tenenhaus M, Vinzi V E, Chatelin Y M and Lauro C 2005 PLS path modelling. Comput. Stat. Data Anal. 48(1): 159-205. doi: 10.1016/j.csda.2004.03.005

Vijande M L S and Gonzalez L L A 2007 TQM and firms performance: An EFQM excellence model research based survey. Int. J. Business Sci. Appl. Manag. 2(2): 21-41 